\title{
The Relationship between ABO Blood Group and Coronary Artery Disease: A Systematic Review and Meta-Analysis
}

\section{Zhao $\mathbf{Q}^{*}$, Chen X, Zhang X, Nie M, Yan Y and Zhao X}

Department of Cardiology, Beijing An-zhen Hospital, Beijing Institute of Heart, Lung and Blood Vessel Diseases, Capital Medical University, Beijing, P.R. China

*Corresponding author: Zhao Q, Department of Cardiology, Beijing An-zhen Hospital, Beijing Institute of Heart, Lung and Blood Vessel Diseases, Capital Medical University, 2 Anzhen Road, Chaoyang District, Beijing 100029, P.R. China, Tel: +86-18910778609; E-mail: zhaoquanming1@sina.com

Received: September 03, 2018; Accepted: October 09, 2018; Published: October 12, 2018

Copyright: ( 2018 Zhao Q, et al. This is an open-access article distributed under the terms of the creative commons attribution license, which permits unrestricted use, distribution, and reproduction in any medium, provided the original author and source are credited.

\begin{abstract}
Background: The coronary artery disease (CAD) is an important risk which causes death and disability. ABO blood group is genetically transmitted through chromosome, which has some role not only in the cholesterol balance and lipid homeostasis but also inflammatory markers and thrombosis. It is supposed to have a role in developing CAD. But the relationship between $C A D$ and $A B O$ blood group is still controversial. Here we conducted a metaanalysis aim to evaluate the role of each blood group on CAD.
\end{abstract}

Method: We searched the related articles from PubMed and Embase which record the patients with CAD and themselves blood group. We compared the risk between each group with the others to evaluate the significance of each group to CAD.

Result: In our analysis, the $O$ group is more frequent in coronary artery disease followed by $A, B$ and $A B$ group successively, which is partly different with previous meta-analysis. Compared with $A$ blood group, $O$ group is more subjected to $C A D(O R=0.97,95 \% \mathrm{Cl}=0.83$ TO $1.14, p=0.73)$ and $A B$ group seem to be a protective factor $(O R=6.52$, $95 \% \mathrm{Cl}=4.83$ to $8.81, \mathrm{p}<0.00001)$.

Conclusion: The statistical significance between $A$ and $O$ is unclear, but there are reasons to believe that blood group influences the incidence of $C A D$. $O$ and $A$ are served as risk factors of $C A D$, when $A B$ group maybe the protective factor. The subsequent mutual comparisons in $B, A B$ and $O$ have the similar results.

Keywords: Coronary artery disease; ABO blood group; Risk factor; Protective factor; Thrombosis

\section{Introduction}

Coronary artery disease is a leading reason of death and disability in the world now [1-5]. Most of this disease comes from atherosclerosis which is a chronic vascular inflammation. Despite advances in cardiovascular therapeutics, atherosclerotic events, such as myocardial infarction (MI) and stoke, continue to account for nearly half of all death and are a leading cause of adult disability [6]. Atherosclerotic plaques, consisting of lipid-laden macrophages and calcification, develop in the coronary arteries, aortic valve, aorta, and peripheral conduit arteries and are the hallmark of cardiovascular diseases [7]. The plaque rupture and subsequent thrombosis are the major mechanisms that cause acute coronary event and serious clinical manifestation.

$\mathrm{CAD}$ is a multifactorial disease whose pathogenesis involving interaction between genetic and environmental factors is complex. [8]. Except for the traditional risk factors such as sex, age, obesity, cigarette smoking, diabetes mellitus, hypertension, dyslipidemia and family history, the blood group may be also associated with CAD $[1,2,9,10]$. Although almost 400 blood group antigens have been reported, the $\mathrm{ABO}$ and $\mathrm{Rh}$ have been recognized as the major clinically significant blood group antigens. The former is more important in relation with CAD [8].
There are some evidences to support this opinion. In 2007, the genome wide association studies (GWAS) for CAD said that CAD locus was on chromosome 9p21 [1,11-13]. The ABO blood group was first found at 1901 and then mapped to chromosome 9 at locus 9p34 [1,13-15]. It seems that blood group is associated with CAD genetically. The $\mathrm{ABO}$ blood group antigens are glycoproteins and glycolipids which expressed on a variety of human tissues including red cells, sensory neurons, platelets, and vascular endothelium $[1,10,14,16,17]$. ABO antigenic determinants expressed on the $\mathrm{N}$ linked chains of circulating plasma von Willebrand factor (VWF) which increases the susceptibility to thrombosis and myocardial infarction. The $\mathrm{ABO}$ is also associated with inflammatory markers such as soluble intercellular adhesion molecule 1, plasma soluble Eselectin levels and P-selectin levels and tumor necrosis factor which are also related to $\mathrm{CAD}[1,2,13,16,18]$. What's more, $\mathrm{ABO}$ blood group can affect circular lipoproteintriglyceride and total cholesterol level and different groups have diverse absorption rates. Cholesterol levels especially the lower-density lipoprotein cholesterol (LDLC) positively associated with CAD $[2,15,19,20]$.

Even so, the real relationship between blood group and CAD has not been clarified absolutely. There are many points about it in different studies. Some studies reported no significant relationship between blood group and the risk of CAD [10,21,22]. Several researches $[1,8]$ demonstrated that $\mathrm{O}$ group was the risk factor for $\mathrm{CAD}$ while someone $[13,16]$ recognized that non-O group was more serve to $\mathrm{CAD}$. Biswas [8] showed that $\mathrm{AB}$ blood group decreases the 
risk of CAD while Lee [9] suggested that A blood group increases the risk of $\mathrm{CAD}$

Because the meta-analysis can assemble enough data and researches to explain clinical problems sufficiently, we now utilize its advantage to explore the relationship between blood group and CAD. Although preceding meta-analysis had studied this problem, different views still exist here. Takagi [23] certified that non-O blood group appears to be an independent risk factor for CAD, but Zhuo Chen [24] thought that risk of CAD was significantly higher in blood group A. Our current study aims to explore the relationship furthermore. The more pathogenesis we master, the more benefit to disease treat.

\section{Methodology}

\section{Search strategy and selection criteria}

This meta-analysis is reported in accordance with the Preferred Reporting Items for Systematic Reviews and Meta-Analyses (PRISMA).

The studies were eligible for inclusion if they compared effects of different $\mathrm{ABO}$ blood groups on $\mathrm{CAD}$. The patients who underwent myocardial infarction (MI), percutaneous coronary interventional (PCI) or coronary artery bypass grafting (CABG) were also included in this study. These studies short of blood group information and with other confounding factors were excluded. There were no limits on the study type.

We selected relevant studies published between Jan 1, 1962 to Dec 31, 2017, by searching PubMed and Embase. We used following contained text and MeSH terms: "ABO blood group" and "coronary artery disease". Various of free terms were also used in the searching process. Two independent investigators (Xue Chen and Xuehui Zhang) reviewed the titles and abstracts, and these matched the inclusion criteria were then retrieved for full-text assessment.

The data extraction was made by two independent investigators to make sure these dates were precise. Those controversial studies that the two investigators can't make decision were sent to the third investigator (Yunfeng Yan) to examine.

We extracted the following contents from each included study: the author and published year, study type, participant amounts, the number of male and female, the number of each blood group and so on. There were also some data calculated by ourselves base on the known message. For example, we used the sum and the man number to get the female population. The age was expressed with mean and standard deviation, if they are available.

Because all the studies included in our meta-analysis are observational studies, we used the Newcastle-Ottawa Scale (NOS) to evaluate the quality of each research.

\section{Statistical analysis}

We assessed the effects of each blood group to CAD by using one group as the experimental group while another group as the control group by turn. We used the software (Review Manager 5.3) to deal with the data and analysis the outcome. The Q test and I2 test were used to assess the heterogeneity between studies. Owing to the obvious heterogeneity, we applied the random effect model (RE) to treat with the data. Because all the included researches are observational studies and extracted data were treated with dichotomous variable, we selected odds ratio (OR) as the effect size and 95\% confidence interval (CI). We assessed the possibility of publication bias by constructing funnel plots.

\section{Results}

We identified 156 articles from the PubMed and Embase and 12 articles (one article contains 3 studies) 25300 participants were included in our study (Figure 1). These studies were all published from 2002 to 2017 and the characteristic and quality of each study were listed in Table 1. The qualities of these studies were assessed on the basis of NOS.

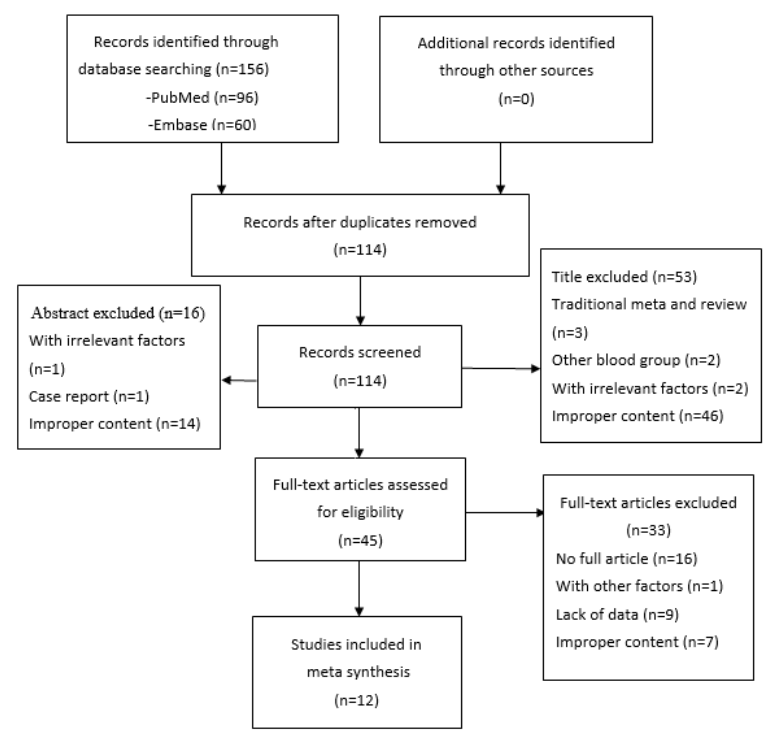

Figure 1: Flow-chart of study selection.

In these studies, four $[1,15,25,26]$ are cross sectional studies, five $[5,8,9,22,27]$ case control studies and three $[4,14,28]$ cohort studies. Because we aimed to compare the effect of each group to the CAD, so all the included studies described four blood groups. Those that are incomplete with data were excluded by us. The blood information of included studies was shown in Table 2.

Because of the obvious heterogeneity in the 14 studies, we conduct subgroup analysis based on the study type and random effect model of each comparison. To explore the source of heterogeneity deeply, we also divided the studies into different races to conduct subgroup analysis. In sensitivity analysis, any excluded study from the analysis didn't significantly affect the results. With regards to the heterogeneity, we have no clear idea about its source. When the A group compared with the other groups, we found that $\mathrm{AB}$ group is a protective factor to $\mathrm{CAD}$ with the statistically significant difference $(\mathrm{OR}=6.52, \mathrm{CI}=4.83$ to 8.81, $\mathrm{p}<0.00001$ ) (Figure 2). 
Citation: Zhao Q, Chen X, Zhang X, Nie M, Yan Y, et al. (2018) The Relationship between ABO Blood Group and Coronary Artery Disease: A Systematic Review and Meta-Analysis. J Cardiovasc Dis Diagn 6: 340. doi:10.4172/2329-9517.1000340

Page 3 of 10

\begin{tabular}{|c|c|c|c|c|c|c|c|}
\hline Author, Year & Race & Type of study & $\begin{array}{l}\text { Total number } \\
\text { of subjects }\end{array}$ & Age & Male & Included criterion & $\begin{array}{l}\text { Quality } \\
\text { study }\end{array}$ \\
\hline Fausto Biancari, 2002 & Finland & cross sectional study & 1152 & 63.3 & 880 & $\begin{array}{l}\text { Patients underwent primary on- } \\
\text { pump coronary artery bypass } \\
\text { surgery from } 1997 \text { to } 2001 \text {. }\end{array}$ & 2 \\
\hline Alireza Amirzadegan, 2006 & Iranian & case-control study & 2026 & 59 & 1512 & $\begin{array}{l}\text { Patients underwent coronary artery } \\
\text { bypass surgery at Tehran Heart } \\
\text { Center from Feb } 2003 \text { to Dec } \\
2003 \text {. }\end{array}$ & 4 \\
\hline $\begin{array}{l}\text { Fernando Henpin Yue } \\
\text { Cesena, } 2006\end{array}$ & Brazilian & cross sectional study & 541 & $57.7 \pm 10.8$ & 384 & $\begin{array}{l}\text { Patients subjected to coronary } \\
\text { bypass grafting, from January } \\
1998 \text { to December,2002, in the } \\
\text { Heart Institute (InCor), Hospital } \\
\text { das Clinicas. }\end{array}$ & 2 \\
\hline Mehmet Kanbay, 2006 & Turkish & retrospective study & 978 & $59.3 \pm 9.7$ & 786 & $\begin{array}{l}\text { patients with multivessel CAD who } \\
\text { had undergone coronary artery } \\
\text { bypass surgery. }\end{array}$ & 4 \\
\hline $\begin{array}{l}\text { Maryam Sotoudeh Anvari, } \\
2009\end{array}$ & Iranian & prospective study & 10641 & $\begin{array}{ll}58.98 & \pm \\
9.61 & \end{array}$ & 7655 & $\begin{array}{l}\text { Patients admitted for CABG at } \\
\text { Tehran Heart Center, Tehran, Iran. }\end{array}$ & 4 \\
\hline Hsin-Fu Lee, 2012 & Taiwanese & case-control study & 136 & $43 \pm 7$ & 86 & $\begin{array}{l}\text { Patients were diagnosed with CAD } \\
\text { through coronary angiography. }\end{array}$ & 5 \\
\hline \multirow{2}{*}{ Massimo Franchini, 2013} & \multirow{2}{*}{ Italy } & \multirow{2}{*}{ case-control study } & \multirow{2}{*}{1879} & \multirow{2}{*}{77} & \multirow{2}{*}{1223} & $\begin{array}{l}1879 \text { consecutive cases of } \mathrm{CHD} \\
\text { were admitted to }\end{array}$ & \multirow{2}{*}{4} \\
\hline & & & & & & $\begin{array}{l}\text { the Emergency Department of the } \\
\text { city Hospital. }\end{array}$ & \\
\hline Santanu Biswas, 2013 & Indian & case-control study & 250 & 54.71 & 204 & $\begin{array}{l}\text { Patients with typical angina and } \\
\text { electrocardiographic study, tread } \\
\text { mill test, stress echo and } \\
\text { echocardiographic evidence of } \\
\text { ischemia or infarction, aged } \\
\text { between } 45 \text { and } 65 \text { years old. }\end{array}$ & 5 \\
\hline Svjetlana Karabuva, 2013 & Croatian & case-control study & 646 & NR & 468 & $\begin{array}{l}\text { Patients with chronic CAD (468 } \\
{[72.4 \%] \text { males) undergoing }} \\
\text { coronary angiography had been } \\
\text { consecutively enrolled. }\end{array}$ & 5 \\
\hline \multirow{3}{*}{ Ping Gong, 2014} & \multirow{3}{*}{ Chinese } & \multirow{3}{*}{ cross sectional study } & 1009 & $56 \pm 10$ & 584 & \multirow{3}{*}{$\begin{array}{l}2919 \text { consecutive patients } \\
\text { undergoing coronary angiography } \\
\text { were enrolled. Based on the } \\
\text { tertiles of GS, the enrolled patients } \\
\text { were classified into the three } \\
\text { groups. }\end{array}$} & \multirow{3}{*}{3} \\
\hline & & & 1008 & $58 \pm 10$ & 727 & & \\
\hline & & & 902 & $59 \pm 10$ & 692 & & \\
\hline \multirow{2}{*}{ Yan Zhang, 2015} & \multirow{2}{*}{ Chinese } & \multirow{2}{*}{ cohort study } & \multirow{2}{*}{3823} & \multirow{2}{*}{ NR } & \multirow{2}{*}{ NR } & $\begin{array}{l}\text { Patients newly referred to our } \\
\text { institution with clinically suspected } \\
\text { or known coronary atherosclerosis }\end{array}$ & \multirow{2}{*}{6} \\
\hline & & & & & & $\begin{array}{l}\text { scheduled for selective coronary } \\
\text { angiography were prospectively } \\
\text { recruited and enrolled. }\end{array}$ & \\
\hline Negar Omidi, 2017 & Iranian & cross sectional study & 309 & $59.6 \pm 11.7$ & 185 & $\begin{array}{l}\text { Patients with moderate to high-risk } \\
\text { unstable angina according to } \\
\text { thrombolysis in myocardial } \\
\text { infarction (TIMI) risk score were } \\
\text { consecutively included into this } \\
\text { study. }\end{array}$ & 3 \\
\hline
\end{tabular}

Table 1: Characteristic and quality of studies. 
Citation: Zhao Q, Chen X, Zhang X, Nie M, Yan Y, et al. (2018) The Relationship between ABO Blood Group and Coronary Artery Disease: A Systematic Review and Meta-Analysis. J Cardiovasc Dis Diagn 6: 340. doi:10.4172/2329-9517.1000340

Page 4 of 10

\begin{tabular}{|l|l|l|l|l|l|}
\hline Study Reference & Sum & A & B & AB & O \\
\hline Fausto Biancari, 2002 & 1152 & 504 & 183 & 109 & 356 \\
\hline Alireza Amirzadegan, 2006 & 2026 & 650 & 503 & 153 & 720 \\
\hline Fernando Henpin Yue Cesena, 2006 & 541 & 213 & 71 & 18 & 239 \\
\hline Mehmet Kanbay, 2006 & 978 & 447 & 147 & 76 & 308 \\
\hline Maryam Sotoudeh Anvari, 2009 & 10641 & 3478 & 2613 & 824 & 3726 \\
\hline Hsin-Fu Lee, 2012 & 136 & 54 & 336 & 5 & 71 \\
\hline Massimo Franchini, 2013 & 1879 & 856 & 179 & 75 & 17 \\
\hline Santanu Biswas, 2013 & 250 & 60 & 77 & 769 \\
\hline Svjetlana Karabuva, 2013 & 646 & 267 & 106 & 45 & 96 \\
\hline \multirow{2}{*}{ Ping Gong, 2014 } & 1009 & 246 & 331 & 103 & 228 \\
\hline Yan Zhang, 2015 & 1008 & 284 & 336 & 115 & 329 \\
\hline Negar Omidi, 2017 & 902 & 266 & 286 & 92 & 273 \\
\hline
\end{tabular}

Table 2: The blood information of each study.

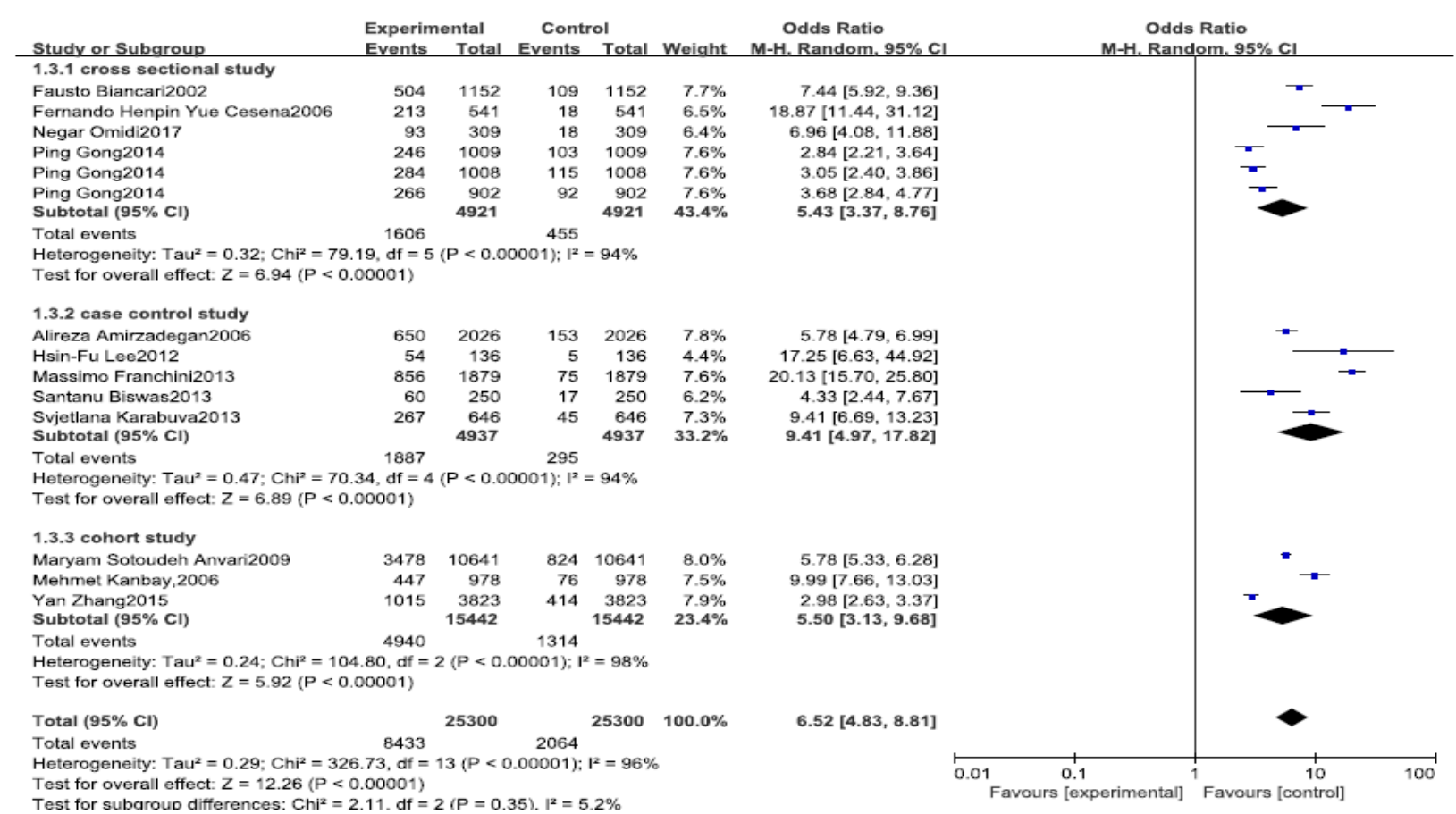

Figure 2: Comparison of group A with other groups. 
Citation: Zhao Q, Chen X, Zhang X, Nie M, Yan Y, et al. (2018) The Relationship between ABO Blood Group and Coronary Artery Disease: A Systematic Review and Meta-Analysis. J Cardiovasc Dis Diagn 6: 340. doi:10.4172/2329-9517.1000340

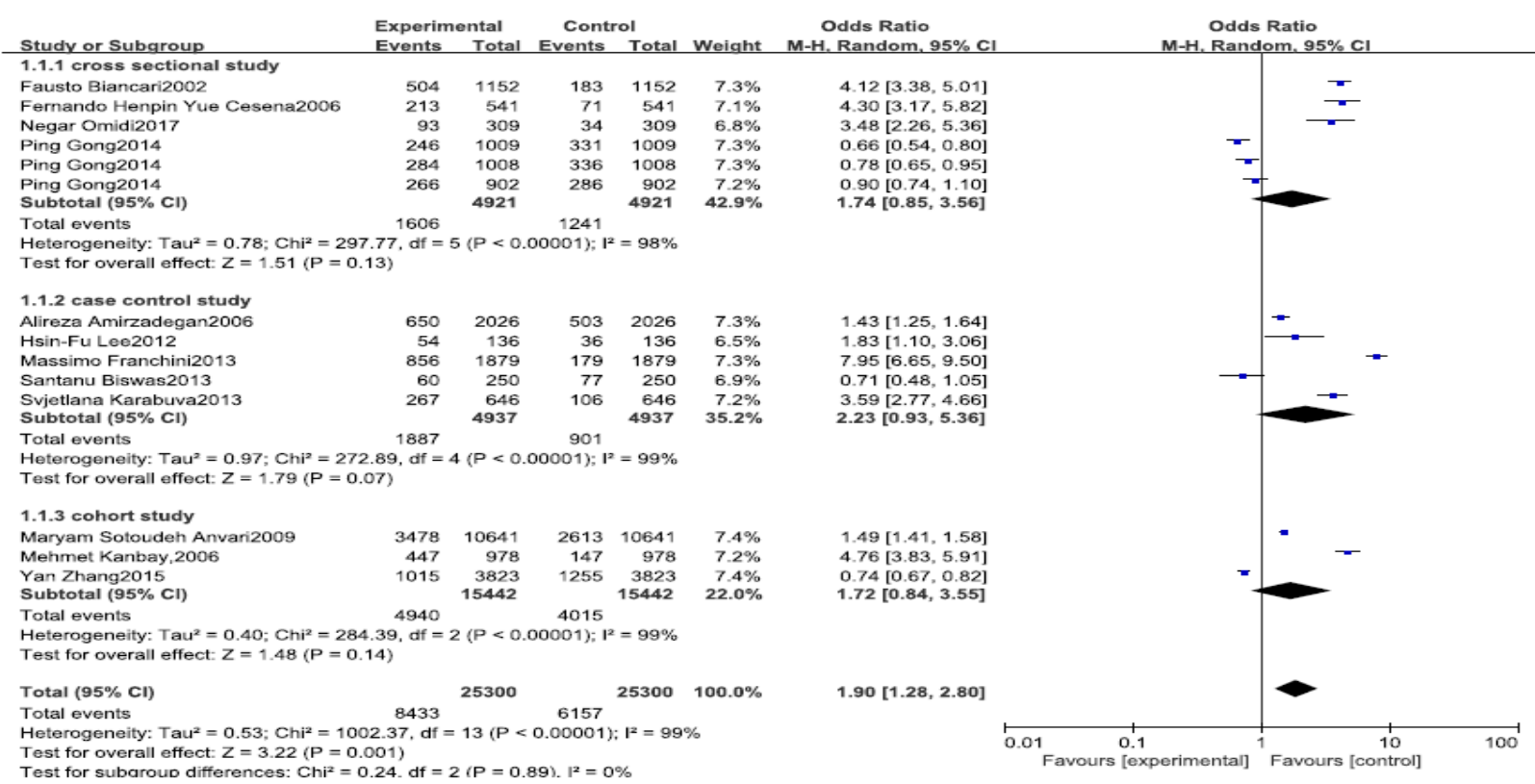

Figure 3: Statistically significant difference between subgroups.

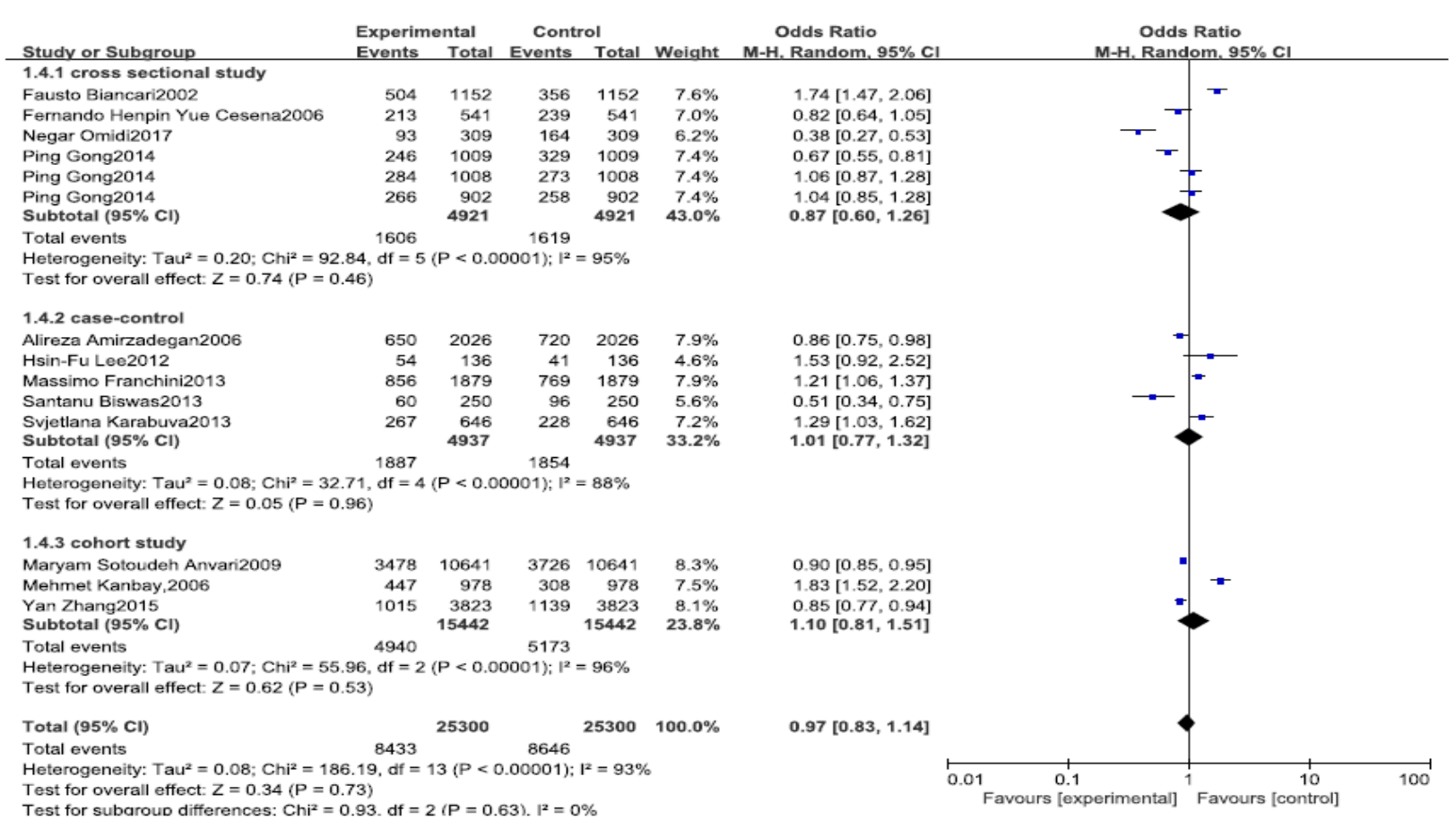

Figure 4: Subgroup analysis. 
Citation: Zhao Q, Chen X, Zhang X, Nie M, Yan Y, et al. (2018) The Relationship between ABO Blood Group and Coronary Artery Disease: A Systematic Review and Meta-Analysis. J Cardiovasc Dis Diagn 6: 340. doi:10.4172/2329-9517.1000340

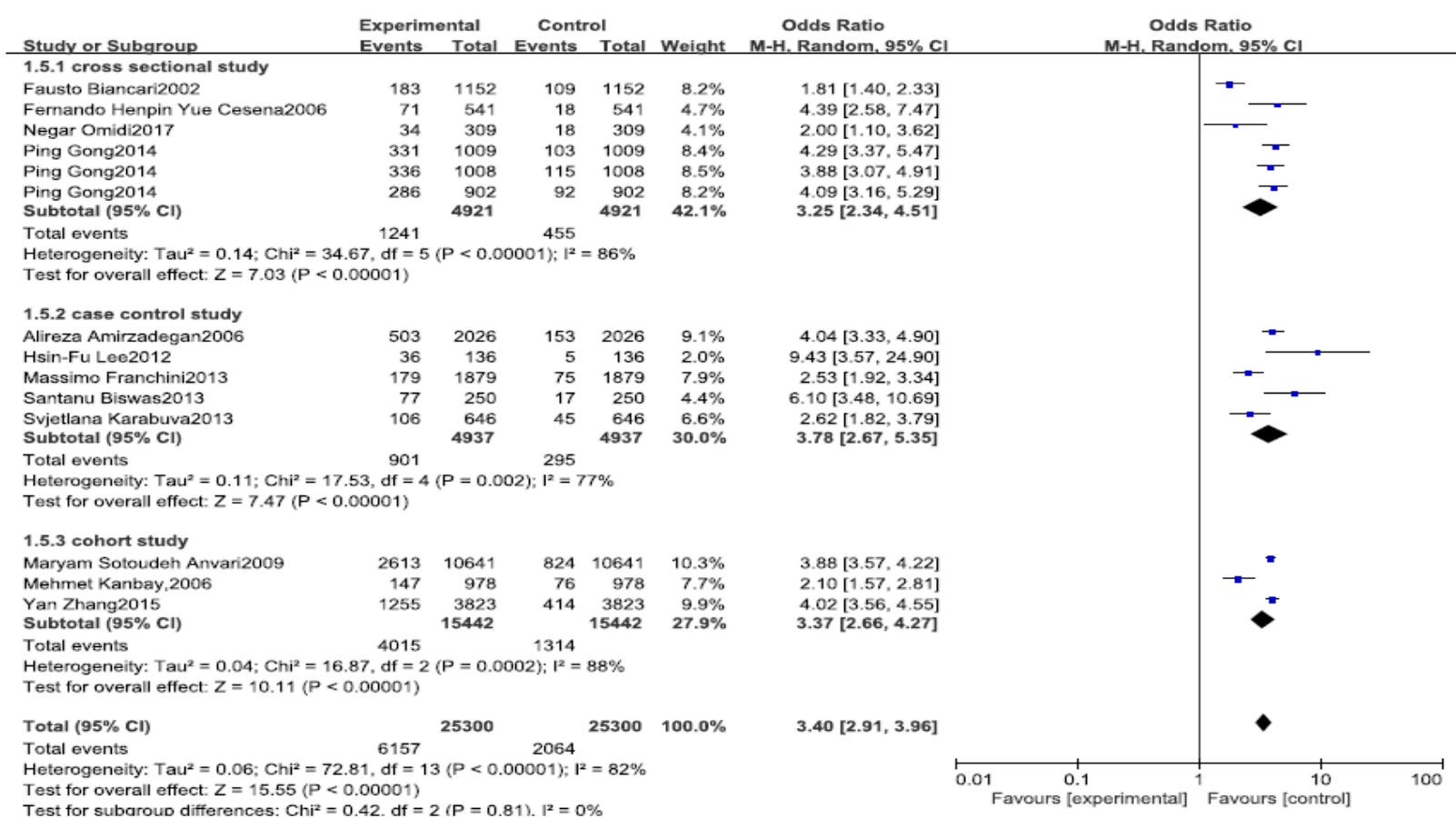

Figure 5: Contrasted B group with $\mathrm{AB}$ and $\mathrm{O}$ group.

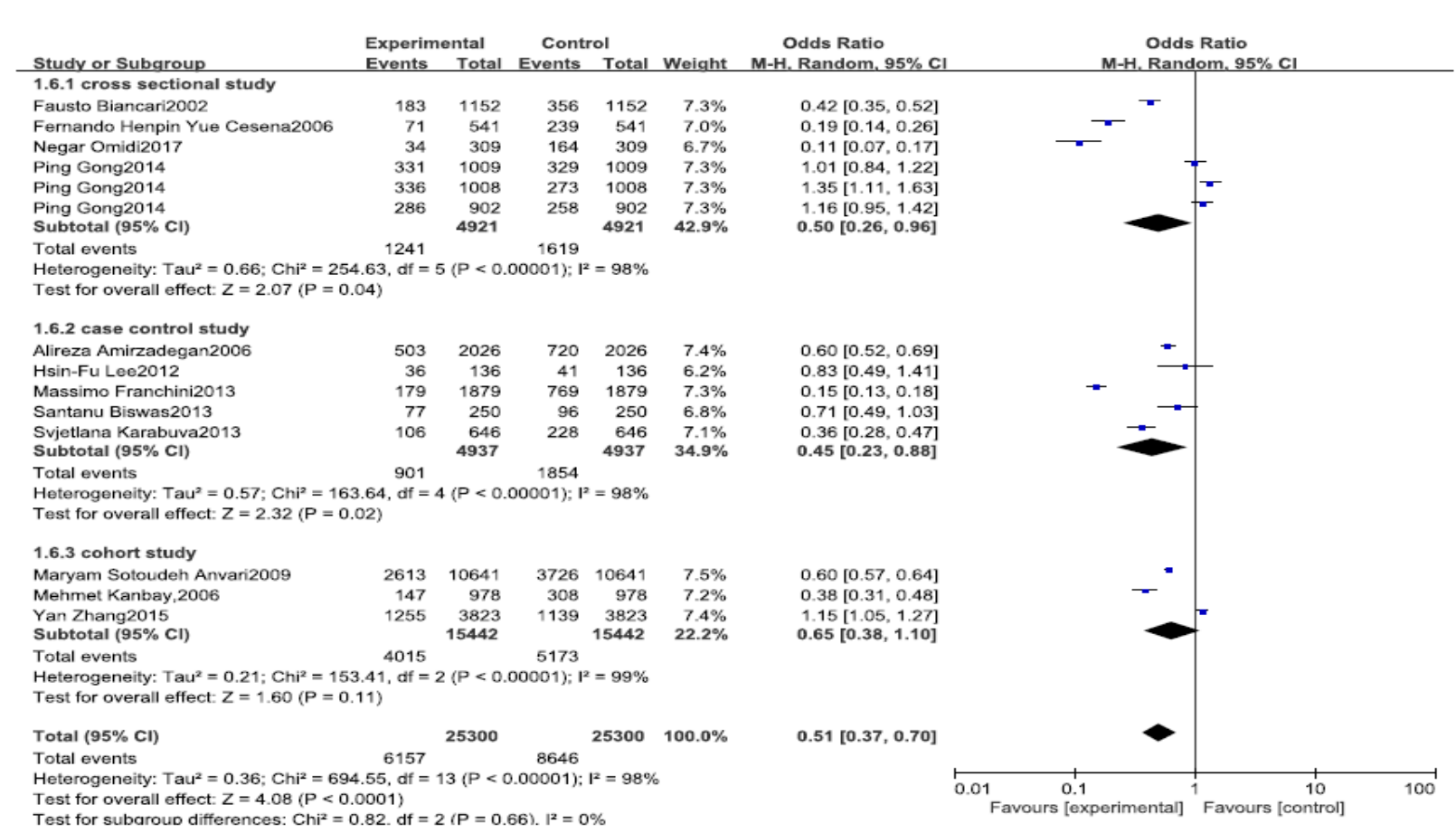

Figure 6: Statistically significant difference between $\mathrm{B}$ group with $\mathrm{AB}$ and $\mathrm{O}$ groups. 
Citation: Zhao Q, Chen X, Zhang X, Nie M, Yan Y, et al. (2018) The Relationship between ABO Blood Group and Coronary Artery Disease: A Systematic Review and Meta-Analysis. J Cardiovasc Dis Diagn 6: 340. doi:10.4172/2329-9517.1000340

Page 7 of 10

The incidence of CAD is also lower in $\mathrm{B}$ group compared with $\mathrm{A}$ group ( $\mathrm{OR}=1.90, \mathrm{CI}=1.28$ to $2.80, \mathrm{p}=0.001)$, but there is no statistically significant difference between subgroups (Figure 3). In compared with $\mathrm{O}$ group, the difference is very little, and no statistically significant difference is presented on both overall effect and subgroup analysis $(\mathrm{OR}=0.97, \mathrm{CI}=0.83$ to $1.14, \mathrm{p}=0.73$ ) (Figure 4$)$.

Then we contrasted $\mathrm{B}$ group with $\mathrm{AB}$ and $\mathrm{O}$ group respectively, which manifested that the incidence is lower in $\mathrm{AB}(\mathrm{OR}=3.40, \mathrm{CI}=2.91$ to $3.96, \mathrm{p}<0.00001)$ while higher in $\mathrm{O}(\mathrm{OR}=0.51, \mathrm{CI}=0.37$ to 0.70 , $\mathrm{p}<0.00001$ ) (Figures 5 and 6 ).
Finally, we assessed the effects between $\mathrm{AB}$ and $\mathrm{O}$ group and the difference is distinct ( $\mathrm{OR}=0.15, \mathrm{CI}=0.11$ to $0.20, \mathrm{p}<0.00001$ ) (Figure 7 ).

From the above, we roughly speculated that the $\mathrm{O}$ blood group is more subject to $\mathrm{CAD}$ followed by $\mathrm{A}, \mathrm{B}$ and $\mathrm{AB}$ group. The results reflected that $A B$ group may decrease the risk of $C A D$ while $A$ and $O$ blood group increase it. Because the charter of our study, we don't assess each group to non-group as previous studies did.

We portrayed some funnel plots in each comparison to evaluate the publication basis, but no evident basis was discovered. We set an example which compared A with B to reveal it in Figure 8.

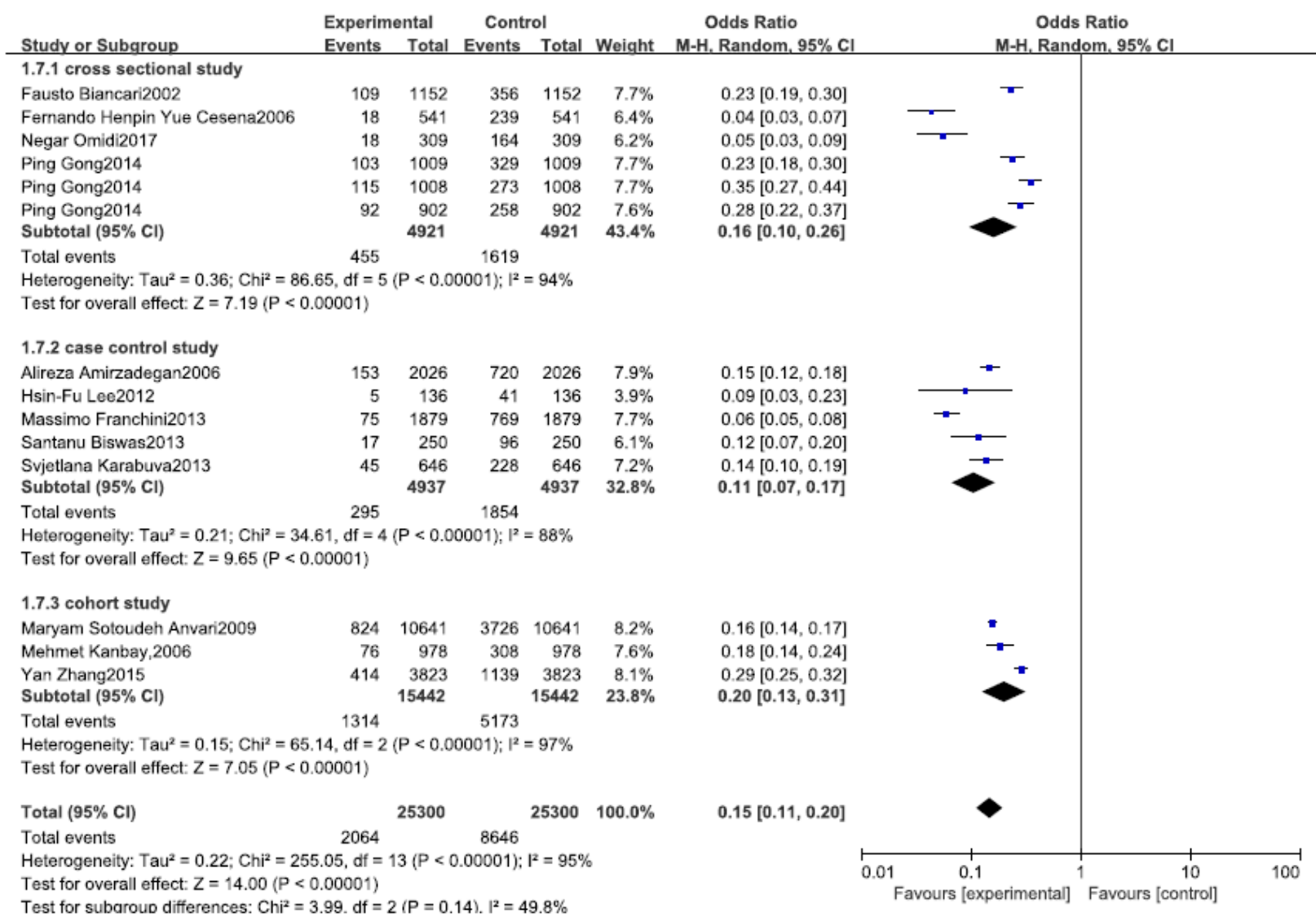

Figure 7: Statistical study between $\mathrm{AB}$ and $\mathrm{O}$ groups. 
Citation: Zhao Q, Chen X, Zhang X, Nie M, Yan Y, et al. (2018) The Relationship between ABO Blood Group and Coronary Artery Disease: A Systematic Review and Meta-Analysis. J Cardiovasc Dis Diagn 6: 340. doi:10.4172/2329-9517.1000340

Page 8 of 10

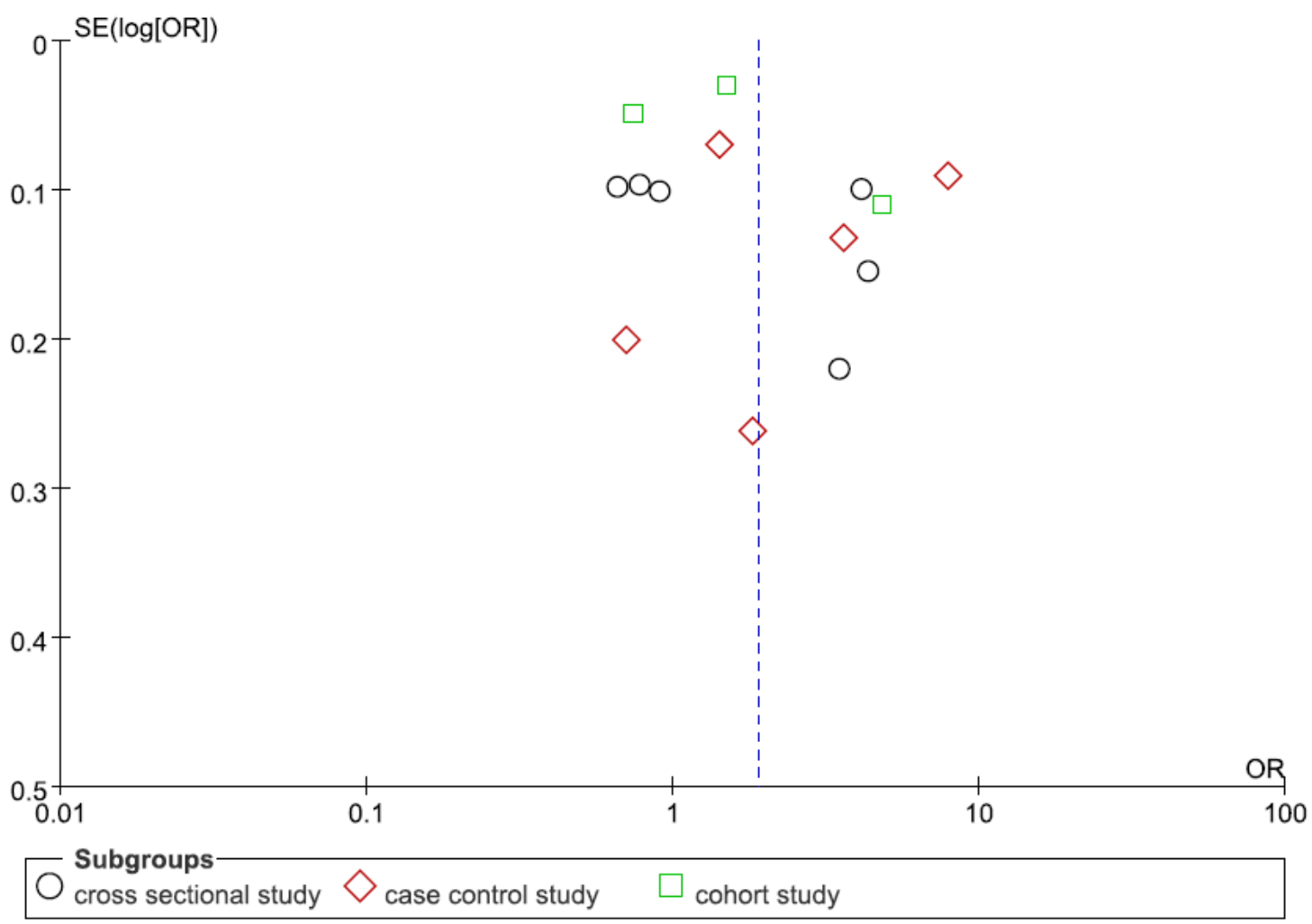

Figure 8: Comparison of A with B groups.

\section{Discussion and Conclusion}

Different with previous studies, we intercompared each blood group to assess the impact to CAD, which was the first study we now known did such research. In conclusion, compared with other groups, $A B$ blood group is the protective factor to $\mathrm{CAD}$ while the $\mathrm{A}$ and $\mathrm{O}$ blood group maybe the risk factors.

Here are several studies that fully or partly agreed with our study. In Biswas's [8] study, they enrolled 250 patients and 250 matched healthy subjects. The analysis showed significant difference in frequency of $\mathrm{O}$ $(\mathrm{OR}=1.857,95 \% \mathrm{CI}=1.112$ to $3.100, \mathrm{p}=0.018)$ and $\mathrm{AB}(\mathrm{OR}=0.447$, $95 \% \mathrm{CI}=0.227$ to $0.882, \mathrm{p}=0.020$ ) blood group between healthy controls and CAD individuals. His study showed that the $\mathrm{AB}$ blood group decreases the risk of CHD in healthy controls, while the O blood group is more frequent in CHD patients and increases the risk of CHD. Lee [9] recruited 265 patients in his study and 136 were diagnosed with CAD when 129 served as controls on the basis of the coronary angiography results. He found that subjects with blood group A had a greater risk of $\mathrm{CAD}$ and $\mathrm{MI}$ than did the non-A blood groups $(\mathrm{OR}=2.08,95 \% \mathrm{CI}=1.23-3.54$; and $\mathrm{OR}=2.21,95 \% \mathrm{CI}=1.19$ to 4.09 , respectively). But he still suggested that subjects with blood group $\mathrm{O}$ were significantly associated with a decreased risk of CAD, not MI $(\mathrm{OR}=0.58,95 \% \mathrm{CI}=0.35$ to 0.96$)$, that is opposite with our current study. Omidi [1] assessed 309 patients with moderate to high-risk unstable angina according to thrombolysis in myocardial infarction. He thought a statistically significant difference between mild, moderate and severe coronary artery involvement with $\mathrm{O}$ and non- $\mathrm{O}$ blood groups $(\mathrm{p}=0.004)$.

There is also previous meta-analysis that only partly agreed or opposite with our results. Zhuo Chen [24] in 2016 extracted 17 studies covering 225810 participants in his study. He found that the risk of CAD was significantly higher in blood group A $(\mathrm{OR}=1.14$, $95 \% \mathrm{CI}=1.03$ to $1.26, \mathrm{p}=0.01)$ and lower in blood group $\mathrm{O}(\mathrm{OR}=0.85$, $95 \% \mathrm{CI}=0.78$ to $0.94, \mathrm{p}=0.0008)$. He indicated that both blood group A and non-O were the risk factors of CAD. Hisato Takagi [23] did his study in 2015 by enrolling 17495 patients in 10 studies and showed that non-O blood group was associated with a statistically significant $14 \%$ increase in CAD incidence relative to O blood group (OR/hazard rations $=1.14,95 \% \mathrm{CI}=1.04$ to $1.25, \mathrm{p}=0.006)$. He demonstrated that non-O blood groups appear to be an independent risk factor for CAD and myocardial infarction.

Apart from the research approach that we intercompared each blood group when previous studies compare one group to non-group in experimental and control groups, many confounding factors such as race, age, smoking and so on that may cause diversities of different studies. Moreover, that possibly relates to the profound mechanism. Although the mechanism that $\mathrm{ABO}$ blood group how to affect CAD hasn't explained clearly, some possible relationships have exhibited in the preceding introduction roughly.

Firstly, it is generally accepted that atherosclerosis is initiated by lipoprotein cholesterol complexes trapped beneath the endothelium [29]. Some studies have proved that different blood types own diverse 
cholesterol absorption rates which are positively associated with cardiovascular risk. Cholesterol might be a mediator of the association of ABO blood group with CAD [15]. Multivariable regression analysis revealed that $\mathrm{ABO}$ group was significantly and independently associated with Proprotein convertase subtilisin/kexin type 9(PCSK9) which is a newly identified member that plays an essential role in cholesterol homeostasis and holds decent promise for hyperlipidemia and CAD treatment. Additionally, mediation analysis indicated that $\approx 8 \%-19 \%$ of the effect of ABO blood group on PCSK9 levels was mediated by total cholesterol (TC), low density lipoprotein cholesterol (LDL-C), or non-high density lipoprotein cholesterol (NHDL-C) levels [30]. Moreover, the ABO blood group associates not only with dyslipidemia but also with blood coagulation, which is an important determinant of plasma factor, von Willebrand factor(vWF) and thrombomdulin [31]. The vWF is a glycoprotein molecule and associated with platelet adhesion, atherosclerosis and thrombosis $[13,32]$. There are also several epidemiological studies shown that higher vWF levels predict increased risk of CAD [33]. Finally, inflammation is a vital characteristic of atherosclerosis. Recently, genome-wide association studies have shown significant associations between genetic variants in the $\mathrm{ABO}$ blood group region and levels of various inflammatory markers including soluble E-selectin, P-selectin, adhesion molecule-1, tumor necrosis factor $[15,31]$. These factors may affect the progress of CAD in a way.

As the various opinion and studies results, we assume that not only the blood group, but also other genetic elements take the effect of CAD [2]. Perhaps, the environment including life style and social customs also plays a role. In our view, the interaction between various risk factors promotes the development of CAD.

According the above discussion, we have reason to believe that the $\mathrm{ABO}$ blood group is correlated with $\mathrm{CAD}$ deeply, despite many confounding factors appear here such as age, race, gender, smoking, obesity and so on.

The study not only contributes us to discover the mechanism of CAD but also benefits to prevent CAD primarily. Those risk population with $\mathrm{A}$ or $\mathrm{O}$ blood group should prevent $\mathrm{CAD}$ as early as they can. For example, they had better control their diet rationally, giving up smoking, limit drinking and do exercise appropriately. What's more, these people should receive closer and more frequent follow up or more aggressive preventive measures.

Although our result receives much support from preceding researches, we still need endeavor to explore the particular relationship between blood group and CAD. Our team is setting out to do next observational study to detect the different distribution between the youth and old who have suffered CAD. Maybe that study can carry some fresh opinion.

\section{Limitation}

Some limitations are here in our study. Firstly, because of the characteristic of observational study, the heterogeneity is distinct. We conduct the subgroup analysis and sensitivity analysis but find no reason. Secondly, the difference of age, gender and lifestyle between each study also cause the basis and heterogeneity. More important, the race difference can affect the result widely, as different races own respective blood group distribution. What's more, not all the blood groups were determined by standard agglutination technique and the criterion of diagnosis to CAD was not consistent. Finally, we paid no attention to some studies whose full text or data are not afforded, which may lead to basis.

\section{Interest conflicts}

The authors claim that there are no conflicts of interest.

\section{Acknowledgement}

This study is supported by National Natural Science Foundation of China (81370437).

\section{References}

1. Omidi N, Khorgami MR, Effatpanah M, Khatami F, Mashhadizadeh M, et al. (2017) Association between ABO blood group and severity of coronary artery disease in unstable angina. ARYA Atheroscler 13: $172-175$.

2. Lukitasari M, Sadewa AH, Rohman MS (2017) ABO gene polymorphism and thrombomodulin-33G $>$ A polymorphism were not risk factors for myocardial infarction in Javanese men. Int J Vasc Med pp: 1-5.

3. Biswas S, Ghoshal PK, Mandal SC, Mandal N (2008) Association of lowdensity lipoprotein particle size and ratio of different lipoproteins and apolipoproteins with coronary heart disease. J Cardiol 52: 118-126.

4. Kanbay M, Yildirir A, Ulus T, Bilgi M, Kucuk A, et al. (2006) Rhesus positivity and low high-density lipoprotein cholesterol: A new link? Asian Cardiovasc Thorac Ann 14: 119-122.

5. Amirzadegan A, Salarifar M, Sadeghian S, Davoodi G, Darabian C, et al. (2006) Correlation between ABO blood groups, major risk factors, and coronary artery disease. Int J Cardiol 110: 256-258.

6. Hammad B, Evans NR, Rudd JH, Tawakol A (2017) Molecular imaging of atherosclerosis with integrated PET imaging. J Nucl Cardiol 24: 938-943.

7. O'Rourke C, Shelton G, Hutcheson JD, Burke MF, Martyn T, et al. (2016) Calcification of vascular smooth muscle cells and imaging of aortic calcification and inflammation. J Vis Exp: 2016.

8. Biswas S, Ghoshal PK, Halder B, Mandal N (2013) Distribution of ABO blood group and major cardiovascular risk factors with coronary heart disease. Biomed Res Int pp: 1-5.

9. Lee HF, Lin YC, Lin CP, Wang CL, Chang CJ, et al. (2012) Association of blood group A with coronary artery disease in young adults in Taiwan. Intern Med 51: 1815-1820.

10. Nafakhi H, Al-Nafakh HA, Al-Mosawi AA (2016) ABO blood group differences relationship with coronary atherosclerotic markers. Artery Res 14: 36-40.

11. Roberts R (2014) Genetics of coronary artery disease. Circ Res 114: 1890-1903.

12. McPherson R, Davies RW (2012) Inflammation and coronary artery disease: Insights from genetic studies. Can J Cardiol 28: 662-666.

13. Carpeggiani C, Coceani M, Landi P, Michelassi C, L’Abbate A (2010) ABO blood group alleles: A risk factor for coronary artery disease. An angiographic study. Atherosclerosis 211: 461-466.

14. Zhang Y, Li S, Zhu CG, Guo YL, Wu NQ, et al. (2015) Risk factors, coronary severity, outcome and ABO blood group: A large Chinese Han Cohort Study. Medicine 94: e1708.

15. Gong P, Luo SH, Li XL, Guo YL, Zhu CG, et al. (2014) Relation of ABO blood groups to the severity of coronary atherosclerosis: An Gensini score assessment. Atherosclerosis 237: 748-753.

16. He M, Wolpin B, Rexrode K, Manson JE, Rimm E, et al. (2012) ABO blood group and risk of coronary heart disease in two prospective cohort studies. Arterioscler Thromb Vasc Biol 32: 2314-2320.

17. Zhou S, Welsby I (2014) Is ABO blood group truly a risk factor for thrombosis and adverse outcomes? World J Cardiol 6: 985-992.

18. Yip SP (2002) Sequence variation at the human ABO locus. Ann Hum Genet 66: 1-27. 
Citation: Zhao Q, Chen X, Zhang X, Nie M, Yan Y, et al. (2018) The Relationship between ABO Blood Group and Coronary Artery Disease: A Systematic Review and Meta-Analysis. J Cardiovasc Dis Diagn 6: 340. doi:10.4172/2329-9517.1000340

Page 10 of 10

19. Chen Y, Chen C, Ke X, Xiong L, Shi Y, et al. (2014) Analysis of circulating cholesterol levels as a mediator of an association between $\mathrm{ABO}$ blood group and coronary heart disease. Circ Cardiovasc Genet 7: 43-48.

20. Silbernagel G, Chapman MJ, Genser B, Kleber ME, Fauler G, et al. (2013) High intestinal cholesterol absorption is associated with cardiovascular disease and risk alleles in ABCG8 and ABO: Evidence from the LURIC and YFS cohorts and from a meta-analysis. J Am Coll Cardiol 62: 291-299.

21. Kaya A, Tanboğa İH, Kurt M, Işık T, Kaya Y, et al. (2014) Relation of ABO blood groups to coronary lesion complexity in patients with stable coronary artery disease. Anadolu Kardiyol Derg 14: 55-60.

22. Karabuva S, Carević V, Radić M, Fabijanić D (2013) The association of $\mathrm{ABO}$ blood groups with extent of coronary atherosclerosis in Croatian patients suffering from chronic coronary artery disease. Biochem Med 23: 351-359.

23. Takagi H, Umemoto $\mathrm{T}$ (2015) Meta-analysis of non-O blood group as an independent risk factor for coronary artery disease. Am J Cardiol 116: 699-704.

24. Chen Z, Yang SH, Xu H, Li JJ (2016) ABO blood group system and the coronary artery disease: An updated systematic review and meta-analysis. Sci Rep 6: 23250.

25. Biancari F, Satta J, Pokela R, Juvonen T (2002) ABO blood group distribution and severity of coronary artery disease among patients undergoing coronary artery bypass surgery in Northern Finland. Thromb Res 108: 195-196.
26. Cesena FH, Da Luz PL (2006) ABO blood group and precocity of coronary artery disease. Thromb Res 117: 401-402.

27. Franchini M, Rossi C, Mengoli C, Frattini F, Crestani S, et al. (2013) ABO blood group and risk of coronary artery disease. J Thromb Thrombolysis 36: 286-287.

28. Anvari MS, Boroumand MA, Emami B, Karimi A, Soleymanzadeh M, et al. (2009) ABO blood group and coronary artery diseases in Iranian patients awaiting coronary artery bypass graft surgery: A review of 10,641 cases. Laboratory Medicine 40: 528-530.

29. Nakahara T, Narula J, Strauss HW (2016) Calcification and Inflammation in Atherosclerosis: Which is the chicken, and which is the egg? J Am Coll Cardiol 67: 79-80.

30. Li S, Xu RX, Guo YL, Zhang Y, Zhu CG, et al. (2015) ABO blood group in relation to plasma lipids and proprotein convertase subtilisin/kexin type 9. Nutr Metab Cardiovasc Dis 25: 411-417.

31. Jenkins PV, O'Donnell JS (2006) ABO blood group determines plasma Von Willebrand factor levels: A biologic function after all? Transfusion 46: $1836-1844$.

32. Ruggeri ZM (2007) The role of Von Willebrand factor in thrombus formation. Thrombo Res 120: S5-S9.

33. Franchini M, Lippi G (2006) Von Willebrand factor and thrombosis. Ann Hematol 85: 415-423. 